\title{
Prevalence and Evaluation of the Use of Electronic Devices in Teaching and Leisure Activities of Pupils 7-8 Classes
}

\author{
Vladislav R Kuchma ${ }^{1}$, Irina K Rapoport ${ }^{1}$, Anna R Virabova ${ }^{1 *}$, Anna Yu Makarova ${ }^{1}$, Nataliya L \\ Yamschikova $^{1}$, Elena V Naryshkina ${ }^{1}$ and Svetlana B Sokolova ${ }^{2}$ \\ ${ }^{1}$ Department of Child and Adolescent Hygiene, FGAU VO "First Moscow State University named after I.M. Sechenov "(Sechenov \\ University) of the Ministry of Health of the Russian Federation Russia, Moscow
}

${ }^{2}$ FSAI "National Medical Research Center for Children's Health" of the Ministry of Health of the Russian Federation

*Corresponding author: Anna R Virabova, Department of Child and Adolescent Hygiene, FGAU VO "First Moscow State University named after I.M. Sechenov" (Sechenov University) of the Ministry of Health of the Russian Federation Russia, Moscow

ARTICLE INFO

Received: 幽 July 13, 2020

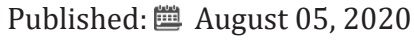

Citation: Vladislav RK, Irina KR, Anna RV, Anna Yu M, Nataliya LY, et al., Prevalence and Evaluation of the Use of Electronic Devices in Teaching and Leisure Activities of Pupils 7-8 Classes. Biomed J Sci \& Tech Res 29(2)-2020. BJSTR. MS.ID.004783.

Keywords: Information and Communication Technologies; Digital School; Visual Impairment; Electronic Devices; Computer Visual Syndrome
ABSTRACT

Introduction: These innovations increase the duration and intensity of student's use of electronic devices with LCD screens: computers, laptops, mobile phones (smartphones), electronic tablets. In one of the schools in Moscow began, the systematic use of electronic tablets in the educational process has begun with the simultaneous use of interactive boards.

Methods: In order to assess the well-being of students in grades 13-15 years, a unified questionnaire survey conducted at the beginning of the school year with the introduction of electronic tablets in the educational process, and it was repeated after 2 months (October-November, 2018 and January, 2019). 224 children were interviewed. Statistical processing was performed using the statistical analysis package Statistica 6.0 (Stat Soft, USA) in 2019. The relationships between the indicators were described by the Pearson conjugacy coefficient (based on Chi-square statistics). Differences were considered statistically significant at $\mathrm{p}<0.05$.

Results: The second survey found an increase in the frequency of complaints indicating the development of neurotic reactions in schoolchildren, the accumulation of fatigue in 52-54\% of schoolchildren throughout the school day with insufficient night rest of children. Girls are found to have statistically more complaints than boys, especially about visual impairment, headaches, fatigue, sleep disorders, neck, back and legs muscle pain.

Conclusion: Gender differences were found in the prevalence of asthenopic complaints. A progressive increase in the number of children with visual impairment is observed in grades 5-7, which requires the use of a complex of preventive measures.

\section{Relevance}

In 2017, the Moscow Electronic School project was launched, and in 2018 the Government of the Russian Federation decided to launch a new priority project "Digital school". Digital devices of the latest generation (interactive boards and panels, computers, tablets, etc.) are widely introduced into the educational process. At the same time, research is being conducted around the world aimed at studying the impact of the modern digital environment on the mental and physical development of children, adolescents and young people, and the data obtained are largely contradictory [19]. Studies performed at the Institute of Hygiene and Protection for children and adolescents of the FGAU "National Medical Research Center of Children's Health" of the Ministry of Health of Russia, other research institutes and medical schools, indicate a deterioration in the health of the younger generation. According to in-depth 
surveys of students conducted during selective scientific research, the leading place in the structure of functional disorders, the first ranking places are occupied by disorders of the cardiovascular system (mainly vegetative-vascular disorders); musculoskeletal system (posture disorders, flattening of the feet, chest deformities); visual disorders (myopia of a weak degree); disorders of the nervous system and the mental sphere (asthenic and neurotic reactions); disorders of the digestive system (functional disorders of the stomach and intestines, biliary dyskinesia); deviations in physical development (excess and deficit of body weight) [10-15].

All of the above health disorders can be attributed to schoolrelated, because in the process of school ontogenesis their prevalence increases, and the course acquires unfavorable trends, especially in the eighth - eleventh grades $[14,16]$. It is assumed that long-term and daily use of information and communication technologies causes fatigue of the Central nervous system, the visual analyzer and the musculoskeletal system, contributes to the development of psychosomatic disorders and generally worsens the well-being of students and leads to the appearance of many complaints $[1-8,10,15,17]$. It is necessary to conduct a serious physiological-hygienic and psychological-pedagogical study of the impact of information and communication technologies on the visual analyzer, physical and mental health of students, as well as to determine the medical consequences of the use of these technologies. This type of research should be systematic and begin with the study of the most characteristic and common complaints made by schoolchildren [18].

\section{Materials and Methods}

Students of grades 7-8 (13-15 years old) were selected to determine the number of children examined, because according to a number of researchers [6,12-14] it is during this period of school ontogenesis that a sharp increase in the prevalence of schoolrelated functional abnormalities and chronic diseases begins. The survey was conducted in two stages. The first stage: 224 students were interviewed, including 105 boys and 119 girls. The second stage: 196 students were interviewed, including 92 boys and 104 girls. These data were initially collected in October-November 2018, and in January 2019, data were obtained for stage 2. Statistical processing was performed using the statistical analysis package Statistica 6.0 (StatSoft, USA) in 2019. The validity of differences between groups was determined by the student's criteria. Differences were considered statistically significant at $p<0.05$. To describe the statistical relationship of qualitative indicators with a small number of discrete variants, we used the construction of conjugacy tables.

The relationships between the indicators were described by the Pearson conjugacy coefficient (based on Chi-square statistics), which is in the range from 0 to 1 . An increase in the coefficient indicates an increase in the degree of connection. For the same purposes, the Kramer coefficient was used according to the method
Of V. E. Deryabin [19]. The sensitive indicators that reflect the state of the visual analyzer, changes in the activity of the Central and vegetative parts of the nervous system, the psycho-emotional state of students, the presence or absence of manifestations of psychosomatic disorders are complaints of children and adolescents. In addition, it was taken into account that long-term use of devices leads to overstrain of certain groups of skeletal muscles and the appearance of complaints of pain in the neck, back, lower back, and joints. It was advisable to use a questionnaire to identify children's complaints. The survey of schoolchildren using a standardized questionnaire has a high sensitivity exceeding $80 \%$, which is proved by scientific research $[17,18,20-24]$. It should be noted that the questionnaire used is anonymous, it only indicates the gender and age of the child.

\section{Research Organization}

The survey of students in grades 7 and 8 was conducted in one of the Moscow secondary schools implementing the project "Analytical support for interactive educational technologies". Two lessons a week in these classes used Samsung electronics tablets with the Android operating system, with a 10-inch diagonal, a screen size of $25 \times 1600$, and a weight of $547 \mathrm{~g}$. All students had personal tablets. The classrooms where classes were held for students in grades 7-8 were equipped with an interactive SMART Board, a direct projection with a diagonal of 77 inches, the size of the interactive surface of $1565 \times 1172 \mathrm{~mm}$. before conducting the research, signed voluntary informed consent was received from the parents of students.

\section{The First Stage}

A survey at the beginning of the school year-at the time of the beginning of the use of electronic tablets in educational activities in the school. The second stage: the survey of the same students using the same questionnaire was conducted after 2 months, when the students adapted to the use of new technologies. All information obtained during the survey was entered in the database.

\section{Results}

Most often, children use mobile phones (mainly smartphones) as a means of communication, communication in social networks, searching for information on the Internet, electronic games, etc. $97.5 \%$ of respondents use them Daily. $51.6 \%$ of students use tablets daily, 38.0\% use computers, and $31.0 \%$ use laptops. For example, $48.7 \%$ of school children use smartphones for more than 4 hours on school days, $55.4 \%$ on weekends, and $47.9 \%$ on holidays; computers and laptops (together) are used by $27.1 \%, 35.0 \%$, and $50.3 \%$, respectively. The use of electronic tablets in the educational process at school increased the time of using the above devices by 2 hours per week. Table 1 provides information on the prevalence of complaints about Central nervous system disorders detected in school children during the first and second surveys. Data from Table 1 indicate a high prevalence of neurotic and asthenic reactions 
among students in grades 7-8. One of the most common complaints is a complaint about headaches that occur more often than once a week. However, girls were twice as likely to report unexplained headaches in the first survey as boys $(27.7 \%$ vs. $14.3 \%$; $<<0.01)$, in the second survey, the difference became even more significant (26.9\% vs. 9.8\% p<0.001).

Table 1: Prevalence of complaints of central nervous system violations.

\begin{tabular}{|c|c|c|c|c|c|c|}
\hline \multirow{2}{*}{ Complaints } & \multicolumn{3}{|c|}{$\begin{array}{l}\text { Prevalence of complaints identified in the first } \\
\text { student questionnaire (September)\% }\end{array}$} & \multicolumn{3}{|c|}{$\begin{array}{l}\text { Prevalence of complaints identified in the second } \\
\text { questionnaire (November) \% }\end{array}$} \\
\hline & $\begin{array}{l}\text { Boys } \\
\mathrm{N}=105\end{array}$ & $\begin{array}{c}\text { Girls } \\
\mathrm{N}=119\end{array}$ & $\begin{array}{l}\text { Both genders } \\
\mathrm{N}=224\end{array}$ & $\begin{array}{c}\text { Boys } \\
\mathrm{N}=92\end{array}$ & Girls N=104 & $\begin{array}{l}\text { Both genders } \\
\quad \mathrm{N}=196\end{array}$ \\
\hline \multicolumn{7}{|l|}{$\begin{array}{l}\text { Headaches (more often } 1 \text { times } \\
\text { a week) }\end{array}$} \\
\hline causeless & 14.3 & $27.7 \#$ & 21.4 & 9.8 & $26.9 \#$ & 19.1 \\
\hline at nervousness & 11.4 & 21.9\# & 16.9 & 18.5 & 20.2 & 19.4 \\
\hline After or at physical load & 7.6 & 15.1 & 11.6 & 7.6 & $17.3 \#$ & 12.8 \\
\hline after visiting school & 12.4 & $36.9 \#$ & 25.4 & $23.9 \#$ & 28.9 & 26.5 \\
\hline In the morning & 5.7 & $14.3 \#$ & 10.3 & $10.8 \#$ & 10.6 & 10.7 \\
\hline $\begin{array}{l}\text { In the evening before going to } \\
\text { bed }\end{array}$ & 3.8 & 10.9 & 7.6 & $11.9 \#$ & $22.1 \#^{* *}$ & $17.3^{* * *}$ \\
\hline Weakness, fatigue after school & 41.9 & $60.5 \#$ & 51.8 & 41.3 & $64.4 \#$ & 53.6 \\
\hline $\begin{array}{l}\text { Tearing (more often } 1 \text { times a } \\
\text { week) }\end{array}$ & 6.7 & $16.8 \#$ & 12.1 & 13.0 & 16.4 & 14.8 \\
\hline frequent mood swings & 20.0 & $38.7 \#$ & 29.9 & 28.3 & $52.8 \# * *$ & $41.3^{* * *}$ \\
\hline $\begin{array}{l}\text { Fear of school attendance } \\
\text { (monitoring, interviewing, etc. }\end{array}$ & 13.3 & 41.2\# & 28.1 & 25.0 & $35.6 \#$ & 30.6 \\
\hline $\begin{array}{l}\text { Sleep disorders including: } \\
\text { long falling asleep }\end{array}$ & 17.1 & $37.8 \#$ & 28.1 & $31.5^{*}$ & 42.3\# & $37.6^{* * *}$ \\
\hline light sleep & 8.6 & 13.1 & 8.9 & 13.4 & 10.6 & 11.7 \\
\hline difficult awakening & 39.1 & $49.6 \#$ & 44.6 & 47.8 & $62.5 \# * *$ & $55.6^{* * *}$ \\
\hline long disinhibition & 10.5 & 15.1 & 12.9 & 11.9 & 17.3 & 14.7 \\
\hline persuasive movements & 20.9 & $30.3 \#$ & 25.9 & 25.0 & $44.2 \# * *$ & $35.2^{* *}$ \\
\hline in total & 233.3 & 429.9 & 355.5 & 319.7 & 472.1 & 400.9 \\
\hline
\end{tabular}

Notes: *Statistically significant difference between the frequency of complaints in boys in the second survey compared to the first survey $(\mathrm{p}<0.05)$;

**Statistically significant difference between the frequency of complaints in girls in the second survey compared to the first survey $(\mathrm{p}<0.05)$;

*** Statistically significant difference between the frequency of complaints in all students (both sexes together) in the second survey compared to the first survey $(\mathrm{p}<0.05)$;

\#Statistically significant difference between the frequency of complaints of boys and the frequency of complaints of girls $(\mathrm{p}<0.05, \mathrm{p}$ $<0.01, \mathrm{p}<0.001)$.

Every fifth or sixth student noted the connection of headaches with anxiety. Girls complained of headaches during agitation more often than boys $(21.9 \%$ vs. $11.4 \%(\mathrm{p}<0.05)$ in the first survey; in the second survey, the gender differences for this complaint were smoothed out. $12-13 \%$ of students report headaches after and during physical activity. The prevalence of this complaint in the group of girls was higher compared to the group of boys, which is reliably confirmed by the data of the second survey: $17.3 \%$ vs. $7.6 \%$, respectively $(\mathrm{p}<0.05)$. One in four respondents indicated that headaches occur after attending school. In addition, this complaint is much more common in the group of girls compared to boys, which was especially noticeable in the first survey $(36.9 \%$ vs. $12.4 \%$; $\mathrm{p}<0.001$ ). In the second survey, the gender difference in indicators decreased markedly. Attention is drawn to the frequency of complaints of headaches in the morning, which affect about $10 \%$ of students. This complaint was almost 3 times more common in girls compared to boys in the first survey $(14.5 \%$ vs. $5.7 \%$; $(\mathrm{p}<0.05)$.

Analysis of the prevalence of complaints of headaches in the evening and before going to bed showed an increase in the second survey: among children of both sexes, from $7.6 \%$ to $17.3 \%(\mathrm{p}<0.05)$; in the group of boys, from $3.8 \%$ to $11,9 \%(p<0.05)$, in the group of girls, from $10.9 \%$ to $22.1 \%(p<0.05)$. There was a significant increase in the frequency of complaints in girls compared to boys according to the second survey: $22.1 \%$ vs. $11.9 \%$ ( $p<0.01$ ). The data obtained indicate fatigue and, in some cases, overwork of students, especially girls, in the afternoon. More than half of students 51.5- 
$53.6 \%$ experience weakness and fatigue after school, and according to the first survey, girls are more likely than boys (60.5\% vs. $41.9 \%$ $(\mathrm{p}<0.001)$. Asthenic reactions, manifested as tearfulness more often than once a week, were noted by 2 times more girls than boys: $16.8 \%$ against $6.7 \%$ in the first survey (the difference is statistically significant $(\mathrm{p}<0.05)$. In the second survey, the gender differences in the frequency of this complaint were smoothed out (13.0\% - boys and $16.4 \%$ - girls).

Similar trends were found when analyzing the prevalence of complaints about frequent mood swings. There was a significant increase in the prevalence of this complaint in the group of girls from $38.7 \%$ to $52.8 \%(\mathrm{p}<0.05)$ and in the whole surveyed student population from $29.9 \%$ to $41.3 \%(\mathrm{p}<0.01)$. The data obtained indicate the accumulated fatigue of students over 2 months of study and the unfavorable psych emotional state of students in the middle of the first half of the school year. $28.1-30.6 \%$ of respondents indicated their fear of school attendance, including the fear of tests, whiteboard surveys, and other types of knowledge testing. In the second survey, the differences in the frequency of this complaint were significantly higher in the boys ' group: $25.0 \%$ vs. $13.3 \%$ $(p<0.01)$. The prevalence of this complaint increased significantly from $28.1 \%$ to $37.6 \%$ during the study period $(\mathrm{p}<0.05)$. A statistically significant increase in the index also occurred in the boys ' group: from $17.1 \%$ to $31.5 \%(\mathrm{p}<0.01)$.

$39.1 \%$ of boys and $49.6 \%$ of girls reported difficulty waking up in the morning during the first survey (the difference is significant $(\mathrm{p}<0.05)$. In the second survey, the indicators increased significantly, especially in the group of girls: from $49.6 \%$ to $62.5 \%$ $(p<0.05)$. In General, the frequency of this complaint increased significantly from $44.6 \%$ to $55.6 \%(\mathrm{p}<0.05)$ for the entire cohort of observed students, which indicates the accumulation of fatigue throughout the day in students and insufficient night rest. Thus, the data from Table 1 shows an increase in the number of complaints among school children during the first 2 months of study, the accumulation of fatigue throughout the day in the observed school children and their insufficient night rest $[1,13,17]$. In addition, girls are much more likely than boys to present all the main complaints that indicate neurotic and asthenic reactions that develop in the course of educational activities. It should be noted that according to the second survey, the gender differences in the prevalence of most of the complaints considered became less pronounced, since the frequency of complaints in the boys 'group increased more than in the girls' group.

Table 2 presents data on the prevalence of complaints among students indicating violations of the functioning of the autonomic nervous system. Complaints that indicate violations of the autonomic nervous system include complaints of increased sweating and the appearance of red spots on the skin during agitation, dizziness, fainting and semi-fainting States, cardialgia, heart palpitations $[12,20,25]$. From $10-14 \%$ of respondents indicated dizziness and instability when changing their body position. The frequency of these complaints is significantly higher in the girls 'group compared to the boys' group, which is confirmed by both surveys. In the first survey, the ratios were: $17.7 \%$ vs. $1.9 \%(\mathrm{p}<0.001)$; in the second, $20.2 \%$ vs. $6.5 \%(\mathrm{p}<0.01)$. Pain and discomfort in the heart region are noted by $9.5 \%$ of boys and $17.7 \%$ of girls, the sex difference is significant $(\mathrm{p}<0.05)$. The second survey showed that the number of boys reporting these complaints decreased to $6.5 \%$, while the number of girls increased to $18.3 \%$, and the reliability of the differences became more pronounced $(p<0.01)$.

Table 2: Prevalence of complaints of vegetative nervous system.

\begin{tabular}{|c|c|c|c|c|c|c|}
\hline \multirow{2}{*}{ Complaints } & \multicolumn{3}{|c|}{$\begin{array}{l}\text { Prevalence of complaints detected while first } \\
\text { questioning of students (September), } \%\end{array}$} & \multicolumn{3}{|c|}{$\begin{array}{c}\text { Prevalence of complaints detected while } \\
\text { second questioning of students (November), \% }\end{array}$} \\
\hline & $\begin{array}{c}\text { boys } \\
\mathrm{n}=105\end{array}$ & $\begin{array}{c}\text { girls } \\
\mathbf{n}=119\end{array}$ & $\begin{array}{l}\text { both genders } \\
\mathrm{n}=224\end{array}$ & $\begin{array}{l}\text { boys } \\
\mathrm{n}=92\end{array}$ & $\underset{n=104}{\text { girls }}$ & $\begin{array}{l}\text { both genders } \\
\mathrm{n}=196\end{array}$ \\
\hline $\begin{array}{l}\text { Excessive sweating or red spots on skin while } \\
\text { feeling excited }\end{array}$ & 4,8 & 7,6 & 6,3 & 6,5 & 9,7 & 8,2 \\
\hline $\begin{array}{l}\text { Dizziness, imbalance while changing a body } \\
\text { position }\end{array}$ & 1,9 & $17,7 \#$ & 10,3 & 6,5 & $20,2 \#$ & 13,8 \\
\hline Fainting, semi-conscious & 0,9 & 5,9 & 3,6 & 0,0 & 2,9 & 1,5 \\
\hline Pain, bad feelings in the heart area & 9,5 & $17,7 \#$ & 13,8 & 6,5 & $18,3 \#$ & 12,8 \\
\hline $\begin{array}{c}\text { Periodic heartbeat, "disruption in heart } \\
\text { activity" }\end{array}$ & 1,9 & 7,6 & 4,9 & 4,3 & 9,6 & 7,1 \\
\hline Total & 19,0 & $56,5 \#$ & 38,9 & 23,8 & 60,7 & 43,4 \\
\hline
\end{tabular}

Note: \# - statically credible distinction in frequency of complaints between boys and girls ( $p<0,05, p<0,01, p<0,001)$.

Thus, according to surveys, the phenomenon of autonomic dysfunction is more common among girls compared to boys. However, there is no data on the increase in the number of complaints about violations of the autonomic nervous system during the two-month use of electronic tablets in the educational process at school. Based on the data from the scientific literature, it was possible to assume a high prevalence and an increase in the frequency of complaints characteristic of computer-visual syndrome (asthenopia) [1,2,15,26]. Table 3 shows complaints that may indicate developing asthenopia. In the first survey, it was 
found that $19.1 \%$ of boys and $46.2 \%$ of girls complain of visual impairment; the gender difference is highly reliable $(\mathrm{p}<0.001)$. Complaints of visual impairment are significantly more common in girls, both in the first survey (46.2\% for girls vs. $19.1 \%$ for boys;

Table 3: Prevalence of complaints of eyesight. $\mathrm{p}<0.001)$ and in the second $(32.7 \%$ for girls vs. $22.8 \%$ for boys; $\mathrm{p}<0.05$ ). Twice as many girls as boys complained of feeling "tired eyes": in the first survey, 48.7\% vs. $21.9 \%$ ( $\mathrm{p}<0.001$ ); in the second survey, $46.2 \%$ vs. $27.2 \%(\mathrm{p}<0.01)$.

\begin{tabular}{|c|c|c|c|c|c|c|}
\hline \multirow{2}{*}{ Complaints } & \multicolumn{3}{|c|}{$\begin{array}{l}\text { Prevalence of complaints, detected while the first } \\
\text { survey of students (September), \% }\end{array}$} & \multicolumn{3}{|c|}{$\begin{array}{l}\text { Prevalence of complaints detected while the } \\
\text { second survey of students (November), \% }\end{array}$} \\
\hline & $\begin{array}{c}\text { boys } \\
\mathrm{n}=105\end{array}$ & $\begin{array}{c}\text { girls } \\
\mathrm{n}=119\end{array}$ & $\begin{array}{l}\text { both genders } \\
\mathrm{n}=224\end{array}$ & $\begin{array}{l}\text { boys } \\
\mathrm{n}=92\end{array}$ & $\begin{array}{c}\text { girls } \\
\mathrm{n}=104\end{array}$ & $\begin{array}{c}\text { both genders } \\
\mathrm{n}=196\end{array}$ \\
\hline Blurred vision & 19,1 & $46,2 \#$ & 33,5 & 22,8 & $32,7 \#$ & 28,1 \\
\hline \multicolumn{7}{|l|}{$\begin{array}{l}\text { Having deteriorating eyesight } \\
\text { do you experience any of the } \\
\text { following: }\end{array}$} \\
\hline -feeling eye fatigue & 21,9 & $48,7 \#$ & 36,2 & 27,2 & $46,2 \#$ & 37,2 \\
\hline - pain in the area of eyes (eyeballs) & 10,5 & 14,3 & 12,5 & 8,7 & $22,1 \#$ & 15,8 \\
\hline -lack of focus & 13,3 & $39,5 \#$ & 27,2 & 15,2 & $26,9 \#$ & 21,4 \\
\hline -seeing spots & 8,6 & $15,9 \#$ & 12,5 & 9,8 & 14,4 & 12,2 \\
\hline -gritty eyes & 4,8 & 10,0 & 7,6 & 6,5 & 13,5 & 10,2 \\
\hline Total & 78,2 & $174,6 \#$ & 129,5 & 90,2 & $155,8 \#$ & 124,9 \\
\hline
\end{tabular}

Note: \# - statically credible distinction in frequency of complaints between boys and girls $(\mathrm{p}<0,05, \mathrm{p}<0,01, \mathrm{p}<0,001)$.

Pain in the eye area (eyeballs) was experienced more often by girls: in the first survey, the difference was not reliable $14.3 \%$ vs. $10.5 \%$, and in the second survey, the difference was statistically significant $(22.1 \%$ vs. $8.7 \% \quad(\mathrm{p}<0.01)$. Girls were three times more likely to complain about blurring images in the first survey compared to boys $(39.5 \%$ vs. $13.3 \%(\mathrm{p}<0.001)$; in the second survey, the difference decreased, but remained reliable $(26.9 \% v s$. $15.2 \%(p<0.05)$. Complaints about the feeling of flashing before the eyes were less often made by boys. In the first survey, the gender difference was significant $(8.6 \%$ vs. $15,9 \%(\mathrm{p}<0.05)$; in the second, the difference was at the trend level of $14.4 \%$ vs. 9.8\% ( $\mathrm{t}=1.92)$. The complaint of "feeling "sand" in the eyes" is more common among girls, but the difference with boys is only at the trend level $(\mathrm{t}=1.92$ at the first examination and $\mathrm{t}=1.97$ at the second examination). Analysis of the conjugacy of complaints made by children using the Deryabin V. E. method [19] did not reveal their conjugation, which indicates that complaints are scattered and there is no convincing evidence of the emerging computer - visual syndrome.

Table 4: Prevalence of complaints, pointing to abnormalities of musculoskeletal system of students.

\begin{tabular}{|c|c|c|c|c|c|c|}
\hline \multirow{2}{*}{ Complaints } & \multicolumn{3}{|c|}{$\begin{array}{l}\text { Prevalence of complaints, detected while the } \\
\text { first survey of students (September), \% }\end{array}$} & \multicolumn{3}{|c|}{$\begin{array}{l}\text { Prevalence of complaints detected while the } \\
\text { second survey of students (November), \% }\end{array}$} \\
\hline & $\begin{array}{c}\text { boys } \\
\mathrm{n}=105\end{array}$ & $\underset{\mathrm{n}=119}{\operatorname{girls}}$ & $\begin{array}{l}\text { both genders } \\
\quad n=224\end{array}$ & $\begin{array}{l}\text { boys } \\
\mathrm{n}=92\end{array}$ & $\underset{\mathbf{n}=104}{\operatorname{girls}}$ & $\begin{array}{c}\text { both genders } \\
n=196\end{array}$ \\
\hline \multicolumn{7}{|l|}{$\begin{array}{l}\text { Pain and/or feeling of heaviness, } \\
\text { including: }\end{array}$} \\
\hline -in neck and back muscles & 11,4 & $31,9 \#$ & 22,3 & 16,3 & $28,9 \#$ & 22,9 \\
\hline -muscles of legs & 21,9 & $31,9 \#$ & 26,8 & 17,4 & $27,9 \#$ & 22,9 \\
\hline $\begin{array}{l}\text { Back pain while walking long } \\
\text { distances and sitting, body leaning }\end{array}$ & 9,5 & 19,3\# & 14,7 & 15,2 & 19,2 & 17,3 \\
\hline \multicolumn{7}{|l|}{ Pain in joints, including: } \\
\hline hip joint & 0,9 & 0,0 & 0,5 & 2,2 & 0,9 & 1,5 \\
\hline knee joint & 13,3 & 15,9 & 14,7 & 10,9 & 14,4 & 12,8 \\
\hline other joints & 7,6 & 5,9 & 6,7 & 7,6 & 6,7 & 7,1 \\
\hline Total & 64,6 & $104,1 \#$ & 85,7 & 69,6 & $98,0 \#$ & 84,5 \\
\hline
\end{tabular}

Note: \# - statically credible distinction in frequency of complaints between boys and girls $(p<0,05, p<0,01, p<0,001)$.

Thus, it was found that complaints about visual disturbances and unpleasant sensations in the eye area are much more common for girls, but there was no increase in the number of these complaints in the process of working with electronic tablets. Table 4 presents complaints that reflect disorders of the musculoskeletal system that may be associated with prolonged tension of the skeletal 
muscles when forced to sit $[8,23,27,28]$. When analyzing the survey data, it was found that girls are significantly more likely to complain of pain in the back and neck muscles than boys: according to the first survey: $31.9 \%$ vs. $11.4 \%$ ( $<<0.001)$, according to the second survey: $28.9 \%$ vs. $16.3 \%(\mathrm{p}<0.01)$. In General, the prevalence of these complaints is $22-23 \%$. Complaints of pain in the leg muscles are noted by $23-27 \%$ of students in grades $7-8$. There were significant gender differences in the prevalence of this complaint, which was more common in girls, both in the first survey $(31.1 \%$ vs. $21.9 \%,(\mathrm{p}<0.05)$, and in the second survey $(27.9 \%$ vs. $17.4 \%$ $(\mathrm{p}<0.05)$. Thus, it was found that girls are significantly more likely to suffer from pain in the muscles of the back, neck and legs than boys. However, during the two-month interval between surveys, the prevalence of these complaints among students, both girls and boys, did not increase.

\section{Conclusions}

1) The study revealed an increase in the number of complaints indicating the development of fatigue and neurotic reactions in students in grades 7-8 during the first two months of the school year. Data from a survey of school children indicate that $52-54 \%$ of the observed students experience fatigue during the entire school day and lack of night rest for children.

2) Statistical analysis of complaints made by children did not establish their correlation, which indicates that the complaints are scattered and there is no convincing evidence of the emerging computer - visual syndrome.

3) According to the survey data, there were significant gender differences in the prevalence of the following complaints:

a) Girls are more likely than boys to complain of visual impairment, a feeling of "eye fatigue", pain in the eye area (eyeballs), blurring of the image, flashing before the eyes, a feeling of " sand in the eyes»;

b) Girls are more likely to indicate that they have complaints indicating the presence of neurotic and asthenic disorders of the personological level (neurotic and asthenic reactions);

c) Girls are more likely to complain of pain in the muscles of the back, neck and legs.

4) There is a progressive increase in the number of children with visual impairments. The most significant growth rate is observed in grades 5-7.

1. The results of the study made it possible to justify a set of preventive measures that should be implemented in schools to prevent overwork of students and the adverse effects of electronic devices. Activities include:

a) Hygienic rational scheduling of lessons using information and communication technologies, b) Hygienically correct organization of the lesson itself, where information and communication technologies are used;

c) Conducting physical training minutes in the classroom with performing gymnastic exercises to relieve tension in the back, neck and legs muscles, as well as performing eye exercises, including using ophthalmic trainers, to relieve tension in the oculomotor and ciliary muscles;

d) Conducting hygienic training and education of schoolchildren for the rational organization of their educational and leisure activities using electronic devices;

e) Hygienic education of parents on the organization of the daily routine and extracurricular activities of children, to reduce the fatigue of training sessions and to include physical education and sports in the leisure activities of students.

2. The purpose of the study was to study the impact of information and communication technologies used in the process of education at school on the well-being of students.

\section{Contribution}

The obtained scientific data will allow us to develop scientifically based recommendations for reducing the adverse impact of electronic devices on the health of schoolchildren.

\section{Acknowledgment}

We wish to acknowledge the school stuff involved in the study, as well as the participants for sharing their data. The authors would like to acknowledge the faculty of the schools. They would also to thank all students who participated in this study.

\section{Funding Sources}

The study was carried out on a grant from the Department of Education in Moscow of First Moscow State Medical University, event No.3 "Medical support for the use of interactive technologies in students' educational activities". (№105 от 27.07.2018 г.).

\section{Disclosure of Potential Conflicts, Real and Perceived, for All}

\section{Named Authors}

All authors confirm no conflict of interest to declare.

\section{References}

1. Stepanova MI, Sazanyuk ZI, Polenov MA (2012) Health saving opportunities of pedagogical technologies. Hygiene and sanitation 2: 52-55.

2. Stepanova MI, Alexandrova IE, Sazanyuk ZI, BZ Voronova, LP Lashneva, et al. (2015) A hygienic regulation of use of electronic educational resources at modern school. Hygiene and sanitation 94(7): 64-68.

3. Chubarovsky VV, Rapoport IK, Sokolova SB, Katenko SV (2015) Problems of cross-disciplinary approach at the organization of psychoprevention among teenage pupils in modern Russia. Health of the population and habitat 11(272): 24-26 
4. Ehlen T, Taylor J, Rowell DP (2016) Are Electronic Devices Affecting My Vision?

5. Jonathan LP, Andrew LF (2016) Depression in children and adolescents. University of Kansas, Clinical Child Psychology Program.

6. Rowan C (2009) The impact of technology on child sensory and motor development. Making Sense of Sensory Processing Disorder.

7. Subrahmanyama K, Patricia G, Robert K, Elisheva G (2011) The impact of computer use on children`s and adolescent`s development. Appl. Develop Psychol 22(1): 7-30.

8. Zulfu Genc (2014) Parents` Perceptions about the Mobile Technology Use Preschool Aged Children. Journal of Procedia - Social and Behavioral Sciences 146: 55-60.

9. Virabova AR (2006) Influence of the personal focused health saving educational environment on the state of health of school students. Materials $\mathrm{V}$ of the International scientific and methodical conference "Current Problems of Preservation and Strengthening of the State of Health of Younger Generation of the Siberian Region". Irkutsk pp. 208210.

10. Baranov AA, Rapoport IK, Sukhareva LM (2014) State of health of modern teenagers. Chapter 1 in the monograph: Medico-social problems of education of teenagers. Monograph М Педиатръ pp. 15-41.

11. Kuchma VR, Sukhareva LM, Rapoport IK (2017) Population health of the children's population, risks to health and sanitary and epidemiologic wellbeing of students: Problems, solutions, technologies of activity. Hygiene and sanitation 10(t.96): 990-995.

12. Poretskova GYu, Tyazheva AA, Rapoport of IK, Voronin EN (2019) Modern trends of violations of health of children of school age Samara. Science and innovations in medicine 4(1): 63-66.

13. Rapoport IK, Sokolova SB, Chubarovsky VV (2014) Zabolevaye most of school students and a problem of creation of the preventive environment in the general education organizations. Questions of school and university medicine and health $3: 10-16$.

14. Rapoport IK, Sukhareva LM (2019) Eleven years' longitudinalny observation: prevalence and a current of functional deviations and chronic diseases at the Moscow school students. Questions of school and university medicine and health 1: 19-27.

15. Rapoport IK, Tsameryan AP (2019) Features of formation of psychological frustration and visual impairment at Moscow studying in the course of training at the Health of the Population and Habitat school (3НисО) 5(314): 20-27.

16. Virabova AR (2012) Development of a health-saving environment in the education system based on the integration of resource support (monograph). Moscow, Probel-2000 pp.151-198.

ISSN: 2574-1241

\section{DOI: 10.26717/BJSTR.2020.29.004783}

Anna R Virabova. Biomed J Sci \& Tech Res

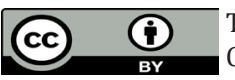

This work is licensed under Creative Commons Attribution 4.0 License

Submission Link: https://biomedres.us/submit-manuscript.php
17. Chubarovsky VV, Labutyeva IS, Kuchma VR (2017) A mental state at the studying teenagers: Retrospective analysis of prevalence of boundary mental disorders. 3НиСО 8(293): 650-653.

18. Baranov AA, Kuchma VR, Sukhareva LM (2008) Assessment of the state of health of children. New approaches to scheduled and improving maintenance in educational institutions: The management for doctors. M. GEOTAR-media.

19. Deryabin VE, Gorbachev AK, Fedotova TK (2007) Influence of medical, social, household, and ecological factors on a constitution of the Moscow children. The manuscript deposited with No 980 VINITI - D2007 of 19.10.2007. M pp. 9-11.

20. M Promedek (1993) The organization of medical control of development and health of preschool children and school students on the basis of mass screening tests and their improvement in the conditions of kindergarten, school.

21. Sotnikova EN, Hramtsov PI (2010) Monitoring of health of children in educational institutions - ways of realization. School of health 4: 7-10.

22. Rapoport IK, Sergeyev AA (2011) Conditions of training and system of observation of the state of health of pupils of elementary grades of rural schools. Health of the population and habitat 6: 39-43.

23. (2012) The guide to diagnostics and prevention shkolno the caused diseases, to improvement of children in educational institutions / under the editorship of VR Kuchma and PI Hramtsova/ M: Publisher of NTsZD, 2012: 181s.

24. (2012) Guide to school medicine. Medical support of children in preschool, educational stitutions and institutions of primary and secondary professional education / under the editorship of VR Kuchma/ M: Publisher of NTsZD, 2012: 215s.

25. Nesterovsky YuE, Zavadenko NN (2014) Primary headaches and cardiovascular violations at children and teenagers. Pediatrics (the magazine of G.N. Speransky) 5: 101-111.

26. De La Paz M, Pico A (2015) Effects of electronic devices on vision.

27. Wordly NB, Kolomna AN, Sinyakina AD (2015) Medico-social importance of violations and diseases of a bone and muscular system of children and teenagers (review of literature). Hygiene and sanitation 3(t.94): 67-69.

28. Sukhareva LM, Namazova Baranova LS, Rapoport IK (2013) Incidence of the Moscow school students in dynamics of training with first on the ninth class. Russian pediatric magazine 4: 48-53.

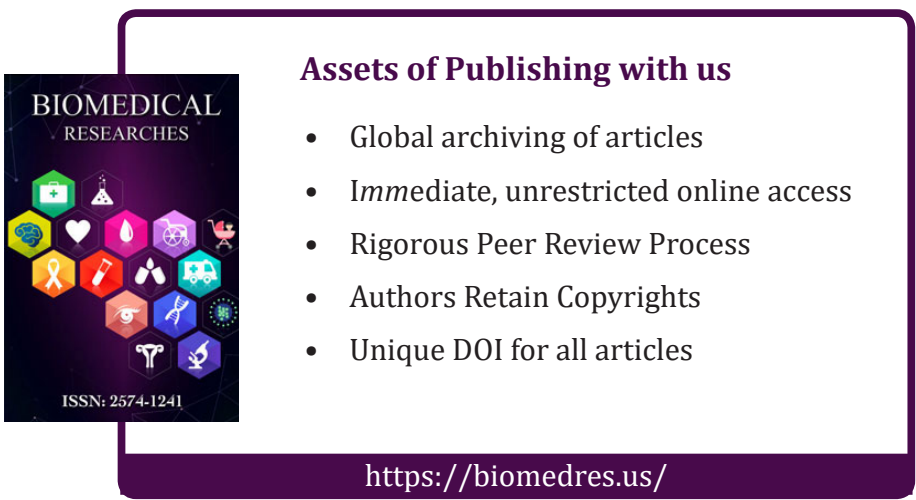

Copyright@ Anna R Virabova | Biomed J Sci \& Tech Res | BJSTR. MS.ID.004783. 